\title{
Low-temperature superplasticity of VT22 titanium alloy
}

\author{
E. Yu. Klassman ${ }^{\dagger, 1}$, V. V. Astanin ${ }^{2}$ \\ †klassman@mail.ru \\ ${ }^{1}$ Institute for Metals Superplasticity Problems RAS, 39 S. Khalturin St., Ufa, 450001, Russia \\ ${ }^{2}$ Ufa State Aviation Technical University, 12 K. Marx St., Ufa, 450008, Russia
}

\begin{abstract}
Characteristics of superplasticity (SP) of ultrafine-grained (UFG) sheets of VT22 titanium alloy with an average grain size of $0.3 \mu \mathrm{m}$ are studied. The UFG microstructure was obtained by severe plastic deformation by means of warm isothermal rolling at a temperature of $540^{\circ} \mathrm{C}$ corresponding to the aging temperature of the VT22 alloy. The paper report on the results of experiments on uniaxial tension of UFG VT22 titanium alloy at the temperatures of 550 and $600^{\circ} \mathrm{C}$ at strain rates within the range of $10^{-4} \mathrm{~s}^{-1}$ to $5 \cdot 10^{-3} \mathrm{~s}^{-1}$. It has been shown that the formation of the UFG microstructure leads to a decrease of the temperature of manifestation of the superplasticity effect in the VT22 titanium alloy by $300^{\circ} \mathrm{C}$ (the VT22 titanium alloy with a fine-grained structure with an average grain size $d=2 \mu \mathrm{m}$ has a traditional SP at $T=860^{\circ} \mathrm{C}$ ). It has been established that UFG VT22 titanium alloy displays superplastic properties at a temperature of $550^{\circ} \mathrm{C}$, and the maximum $\mathrm{SP}$ (a strain rate sensitivity factor $m=0.45$, an elongation $\delta=620 \%$ ) is observed at $600^{\circ} \mathrm{C}$. At a temperature of $550^{\circ} \mathrm{C}$, the SP maximum is observed at strain rate of $10^{-4} \mathrm{~s}^{-1}$. An increase in the temperature to $600^{\circ} \mathrm{C}$ results in a shift in the maximum values of SP towards higher strain rates. Microstructural and fractographic studies of the low-temperature SP effect of the UFG VT22 alloy revealed the absence of significant grain coarsening during superplastic deformation. The failure of the samples at the studied temperatures is likely due to cracking of the oxide film and the penetration of cracks into the sample during the tensile test.
\end{abstract}

Keywords: ultrafine-grained structure, superplasticity, titanium alloy VT22.

УДК: 620.178.74, 620.172.24

\section{Низкотемпературная сверхпластичность титанового сплава ВТ22}

\author{
Классман Е. Ю., ${ }^{\dagger,}$, Астанин В. В. ${ }^{2}$ \\ ${ }^{1}$ Институт проблем сверхпластичности металлов РАН, ул. С. Халтурина, 39, Уфа, 450001, Россия \\ ${ }^{2}$ Уфимский государственный авиационный технический университет, ул. К. Маркса, 12, Уфа, 450008, Россия
}

Исследованы характеристики сверхпластичности (СП) листовых заготовок из титанового сплава ВТ22 с ультрамелкозернистой (УМЗ) структурой со средним размером зерен 0.3 мкм. УМЗ состояние было получено интенсивной пластической деформацией путем теплой изотермической прокатки при температуре $540^{\circ} \mathrm{C}$, соответствующей температуре старения сплава ВТ22. Представлены результаты экспериментов по одноосному растяжению титанового сплава ВТ22 с УМЗ структурой при температурах 550 и $600^{\circ} \mathrm{C}$ в интервале скоростей деформации $10^{-4} \mathrm{c}^{-1} \ldots 5 \cdot 10^{-3} \mathrm{c}^{-1}$. Показано, что измельчение зерен до УМЗ состояния приводит к снижению температуры проявления эффекта сверхпластичности в титановом сплаве ВТ22 примерно на $300^{\circ} \mathrm{C}$. Нижняя температура, при которой выявили признаки СП для титанового сплава ВТ22 в УМЗ состоянии, составила $550^{\circ} \mathrm{C}$. Для сравнения, титановый сплав ВТ22 с мелкозернистой структурой со средним размером зерен $d \sim 2$ мкм обладает традиционной СП при $860^{\circ} \mathrm{C}$. Показано, что максимальная СП (коэффициент скоростной чувствительности напряжения течения $m=0.45$ и относительное удлинение $\delta=620 \%$ ) наблюдается при $600^{\circ} \mathrm{C}$. При температуре $550^{\circ} \mathrm{C}$ максимум СП приходится на скорость $10^{-4} \mathrm{c}^{-1}$, а при повышении температуры до $600^{\circ} \mathrm{C}$ максимальные показатели смещаются в сторону больших скоростей деформации. Микроструктурные и фрактографические исследования эффекта низкотемпературной сверхпластичности УМЗ сплава ВТ22 выявили отсутствие резко выраженного укрупнения зерен при сверхпластической деформации. Разрушение образцов при исследованных температурах, вероятно, связано с растрескиванием оксидной плёнки и проникающим ростом трещин в объем образца в процессе испытания растяжением.

Ключевые слова: ультрамелкозернистая структура, сверхпластичность, титановый сплав ВТ22. 


\section{1. Введение}

В настоящее время развитие различных отраслей машиностроения требует создания новых конструкционных материалов, обладающих повышенной технологичностью при формообразовании изделий со сложной пространственной конфигурацией. Увеличивается применение сплавов на основе титана, алюминия, магния, высокие прочностные и эксплуатационные свойства которых в сочетании с малой плотностью позволяют создавать из них надежные долговечные изделия и конструкции [1-3]. Однако, для получения из этих сплавов деталей даже относительно простой формы листовой штамповкой требуется мощное прессовое оборудование и, кроме того, большое число технологических операций с многочисленными промежуточными отжигами [4]. При этом низкие пластические свойства приводят, как правило, к дефектам в готовой продукции, большим потерям дорогостоящего металла и снижению эффективности процесса [5].

Комплексно-легированный титановый сплав ВТ22 отличается максимальным эффектом упрочняющей термообработки, относится К классу наиболее высокопрочных титановых сплавов, поставляется в виде крупногабаритных полуфабрикатов с крупнозернистой структурой. Между тем, в авиационном машиностроении наблюдается повышенный интерес к изготовлению полых тонкостенных изделий с высокими прочностными свойствами, технологически достижимом при использовании сверхпластической деформации. Эффект низкотемпературной СП является крайне интересным явлением, востребованным для решения не только технологических проблем формообразования, но и возможности одновременного снижения энергоемкости производственного процесса и повышения качества получаемых полых изделий ответственного назначения [6]. Наблюдается интерес к технологиям, основанным на использовании эффекта традиционной и низкотемпературной СП, таким как объемная штамповка в режиме СП, сверхпластическая формовка листовых заготовок, сварка давлением (диффузионная сварка) [7-9], так как они позволяют получать востребованные для авиастроения и других областей высокопрочные полые конструкции сложной формы [10,11].

Стоит отметить, что для двухфазных титановых сплавов, которые наиболее изучены и для которых уже разработаны технологии изготовления изделий с использованием СП, возможно снижение нижней температуры эффекта СП на $150-400^{\circ} \mathrm{C}$ [12]. Низкотемпературная СП титанового сплава ВТ6 в УМЗ состоянии позволяет существенно улучшить экономические показатели технологии и качество изготавливаемых полых изделий, например, полой широкохордной лопатки [13].

Известно [12], что высокопрочный комплекснолегированный мелкозернистый титановый сплав ВТ22 (средний размер зерен $d \sim 2$ мкм) обладает традиционной СП при температуре деформации $T=860^{\circ} \mathrm{C}\left(\grave{\varepsilon}=10^{-3} \mathrm{c}^{-1}\right.$, $m=0.5)$. Для УМ3 сплава ВТ22 присуще уникальное для титановых сплавов одновременное повышение как прочностных характеристик, так и ударной вязкости [14].

В работе [15] показано, что сплав Ti-5Al-5Mo-5V-1Cr-1Fe c ультрамелкозернистой структурой $(d \sim 0.15$ мкм $)$ показывает удлинение до разрушения выше $300 \%$. УМЗ структура была получена методом интенсивной пластической деформации (ИПД) - прессованием, что весьма трудоёмко и затратно. В случае листовой прокатки появляется уникальная возможность создавать УМЗ структуру в процессе получения фольги или тонкого листа [16]. Особенно эффективна изотермическая прокатка в режиме близком к сверхпластичности (СП), когда существенная доля деформации осуществляется зернограничным проскальзыванием, размывающим текстуру и формирующим структуру границ зерен [17].

Целью настоящей работы является исследование СП при пониженных температурах в листовых заготовках титанового сплава ВТ22 с УМЗ структурой, полученных изотермической прокаткой.

\section{2. Материал и методики исследования}

Объектом исследования были листовые заготовки из высокопрочного комплексно-легированного титанового сплава ВТ22. Исходное состояние - пруток горячего промышленного проката диаметром 60 мм, со средним размером зерна $d \sim 100$ мкм. Химический состав исследуемого сплава соответствует ГОСТ 19807-91: Ti-5.1Al-5.1Mo-4.9V-1.3Cr-1.3Fe. Измельчение зерен до УМЗ состояния осуществляли путем прокатки в две стадии. На первой стадии проводили горячую прокатку в $(\alpha+\beta)$-области на стане ДУО-300 со скоростью деформации $\sim 10^{-1} \mathrm{c}^{-1}$ при начальной температуре $850^{\circ} \mathrm{C}$. При этом суммарная логарифмическая степень деформации на данной стадии составляла $e=1.8$. После горячей прокатки полученные полосы закаливали с температуры $780^{\circ} \mathrm{C}$ в воду. На второй стадии проводили изотермическую прокатку (ИТП) на лабораторном изотермическом прокатном стане ЛИС-6/200 при температуре $540^{\circ} \mathrm{C}$, соответствующей температуре старения сплава, таким образом совмещая процесс измельчения структуры с упрочняющей термической обработкой [16]. Величина обжатия за проход выбиралась такой, чтобы обеспечить скорость в очаге деформации $4 \cdot 10^{-3} \mathrm{c}^{-1}$, что соответствовало верхней границе оптимального интервала скоростей СП [17]. Данный режим прокатки обеспечивает однородное формирование УМЗ структуры ( $d \sim 0.3$ мкм) по всей ширине листа. Суммарная логарифмическая степень изотермической деформации составляла $e=1.6$. После изотермической прокатки полосы подвергались отжигу для снятия напряжений при температуре $T=550^{\circ} \mathrm{C}$ [18].

Исследования изломов образцов после испытаний проводили на растровом электронном микроскопе Mira 3 Tescan LMN. Для изучения деформационного рельефа и определения шероховатости поверхности 
образцов была применена методика сканирующей зондовой микроскопии (С3М). Шероховатость поверхности $R_{a}$ рассчитывали для участка рабочей части образца $(\varepsilon=300 \%)$.

Механические испытания на растяжение проводили на универсальном динамометре Instron-1185 при температурах 550 и $600^{\circ} \mathrm{C}$ и скоростях деформации от $10^{-4} \mathrm{c}^{-1}$ до $5 \cdot 10^{-3} \mathrm{c}^{-1}$. После испытаний определяли деформационные характеристики: напряжение течения, рассчитанное при $\varepsilon=30 \%$, относительное удлинение до разрушения $\delta$, коэффициент скоростной чувствительности напряжения течения $m$.

\section{3. Результаты и обсуждение}

Изотермической прокаткой в сплаве ВТ22 была сформирована УМ3 структура (Рис. 1): зерна $\alpha$ - и $\beta$-фаз преимущественно равноосные, без заметной вытянутости, со средним размером $d \sim 0.3$ мкм.

Как показали результаты механических испытаний на растяжение (Рис. 2, Табл. 1), при температуре $T=600^{\circ} \mathrm{C}$, исследуемый сплав ВТ22 со средним размером зерен $d \sim 0.3$ мкм, имеет удлинение более $\delta=600 \%$, что свидетельствует о наличии высокого потенциала технологической пластичности в условиях низкотемпературной СП $[19,20]$.

Анализ результатов механических испытаний, представленный в Табл. 1, позволяет утверждать о проявлении низкотемпературной сверхпластичности в титановом сплаве ВТ22 с УМЗ структурой, что в целом типично для двухфазных титановых сплавов с уменьшением среднего размера зерен до уровня в интервале от 0.1 мкм и до 1 мкм $[15,21]$. Нижняя температура, при которой выявили признаки СП для титанового сплава ВТ22 в УМЗ состоянии составила $550^{\circ} \mathrm{C}$, что на $\sim 300^{\circ} \mathrm{C}$ ниже для того же сплава, в МК состоянии [12].Использованиеизотермической прокатки для измельчения структуры, позволяет реализовать в данном сплаве эффект низкотемпературной СП при размере зерен $d \sim 0.3$ мкм, измельчение структуры иным методом ИПД [15] позволяет реализовать данный эффект при $d \sim 0.15$ мкм.

В Табл. 1 представлены зависимости напряжения течения $\sigma_{30}$, относительного удлинения $\delta$ и коэффициента скоростной чувствительности $m$ от скорости деформации при температурах 550 и $600^{\circ} \mathrm{C}$.

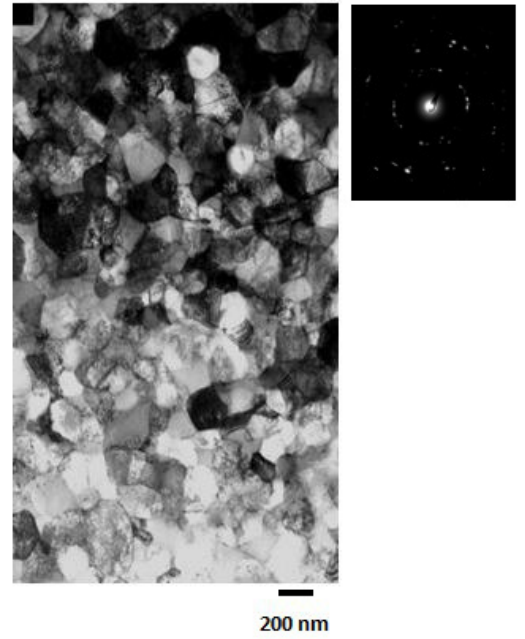

Рис. 1. Микроструктура тонких листов титанового сплава ВТ22 после изотермической прокатки.

Fig. 1. The microstructure of thin sheets of titanium alloy VT22 after isothermal rolling.

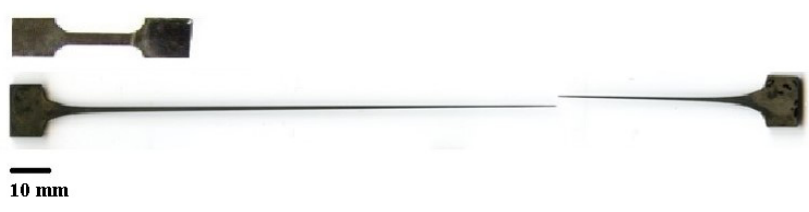

Рис. 2. Исходный (верхний) и растянутый в условиях низкотемпературной сверхпластичности при температуре $600^{\circ} \mathrm{C}$ образец (нижний) из титанового сплава ВТ22.

Fig. 2. View of an initial VT22 alloy sample (an upper one) and a VT22 alloy sample after tension under conditions of lowtemperature superplasticity at a temperature of $600^{\circ} \mathrm{C}$ sample (a lower one).

При температуре $550^{\circ} \mathrm{C}$ максимум СП наблюдается при скорости $10^{-4} \mathrm{c}^{-1}$. При повышении температуры до $600^{\circ} \mathrm{C}$ максимальные показатели СП смещаются в сторону больших скоростей деформации.

Электронно-микроскопические исследования микроструктуры образцов после испытаний на СП в рабочей части и в зоне захватов (Рис. 3) показали типичные признаки того, что титановый сплав деформировался в состоянии СП $[22,23]$ : равноосность зерен в рабочей части испытанных образцов, отсутствие пор и следов их зарождения на отполированной

Табл. 1.Зависимости напряжения течения $\sigma_{30}$, относительного удлинения $\delta$ и коэффициента $m$ сплава ВТ22 от скорости деформации при температурах 550 и $600^{\circ} \mathrm{C}$.

Table 1. The dependence of stress $\sigma_{30}$, relative elongation $\delta$ and coefficient $m$ of VT22 alloy on a strain rate at temperatures of 550 and $600^{\circ} \mathrm{C}$.

\begin{tabular}{|c|c|c|c|c|c|c|}
\hline & \multirow{2}{*}{$\begin{array}{c}\text { Temпература, }{ }^{\circ} \mathrm{C} \\
\text { Temperature, }{ }^{\circ} \mathrm{C}\end{array}$} & \multicolumn{5}{|c|}{$\begin{array}{c}\text { Скорость деформации, } \dot{\varepsilon}, \mathrm{c}^{-1} \\
\text { Strain rate, } \dot{\varepsilon}, \mathrm{s}^{-1}\end{array}$} \\
\cline { 3 - 8 } & & $10^{-4}$ & $5 \cdot 10^{-4}$ & $10^{-3}$ & $2 \cdot 10^{-3}$ & $5 \cdot 10^{-3}$ \\
\hline \multirow{2}{*}{$\begin{array}{c}\sigma_{30}, \mathrm{M \Pi a} \\
\sigma_{30}, \mathrm{MPa}\end{array}$} & 550 & 260 & 407 & 430 & 520 & 650 \\
\hline \multirow{2}{*}{$\delta \%$} & 600 & 80 & 111 & 150 & 180 & 206 \\
\cline { 2 - 8 } & 550 & 211 & 105 & 94 & 76 & 50 \\
\hline \multirow{2}{*}{$m$} & 600 & 330 & 383 & 620 & 470 & 272 \\
\cline { 2 - 8 } & 550 & 0.35 & 0.25 & 0.21 & 0.13 & 0.08 \\
\hline
\end{tabular}




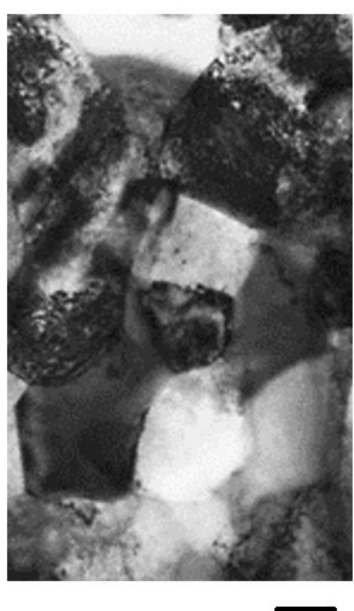

$200 \mathrm{~nm}$

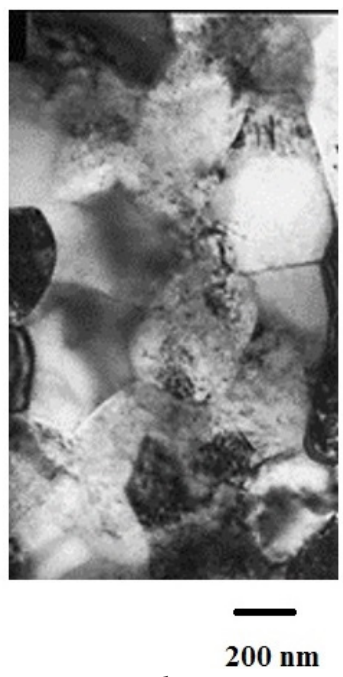

b a

Рис. 3. Тонкая структура растянутого при $600^{\circ} \mathrm{C}$ образца из сплава ВТ22 в зоне захвата (а) и в центральной части рабочей зоны (b).

Fig. 3. The fine structure of a sample of VT22 alloy stretched at $600^{\circ} \mathrm{C}$ in the capture zone (a) and in the central portion of the working area (b).

поверхности образцов после растяжения на установившейся стадии сверхпластического течения. Металлографический анализ структуры выявил и отличительную особенность: по сравнению с двухфазным титановым сплавом ВТ6 [23], в сплаве ВТ22 отсутствует укрупнение зерен при сверхпластической деформации в условиях низкотемпературной СП.

Появление на поверхности деформационного рельефа обычно связывают с развитием зернограничного проскальзывания (ЗГП) - основного механизма сверхпластической деформации [22,24]. На Рис. 4 а видны следы разрушения оксидной плёнки, образующие систему крупных и мелких деформационных полос, связанных с границами зерен. В процессе испытаний при повышенных температурах поверхность покрыта оксидной плёнкой, которая, разрушаясь, обозначает места наиболее интенсивной деформации. В ходе деформации в оксидной пленке образуются трещины (показано стрелками), в которые проникает кислород, дополнительно окисляя поверхность сплава (Рис. 4b), что, возможно, снижает значения относительного удлинения.

Поверхность излома испытанных образцов типична для деформированых при повышенной температуре. Характер разрушения материала в центральной объемной части образца вязкий и осуществляется путем отрыва по механизму образования фасеток (Рис. 4c) ямки равноосные, почти одинаковых размеров, фасеток скола не наблюдается.

Важным фактором при оценке возможности использования материала для изготовления высокопрочных полых конструкций сложной формы, основанного на использовании эффекта традиционной и низкотемпературной СП, является уровень шероховатости внешних и внутреннихповерхностей [11]. Для титанового сплава ВТ22 при температурах 600 и $550^{\circ} \mathrm{C}$ параметр шероховатости $R_{a}$ составил 0.3 и 0.2 мкм соответственно, что существенно ниже, чем при традиционной СП мелкозернистого титанового сплава ВТ6 [24].

Исходя из высокого потенциала технологической пластичности у исследуемого сплава ВТ22 в условиях низкотемпературной СП, а также высокой прочности и ударной вязкости в УМЗ состоянии [14], данный сплав может быть успешно использован для формообразования полых деталей ответственного назначения, например, путем изотермической штамповки.

\section{4. Выводы}

1. Изотермической прокаткой получены УМ3 листы со средним размером 0.3 мкм из комплекснолегированного титанового сплава ВТ22. Установлено наличие низкотемпературной СП в титановом сплаве BT22: титановый сплав ВТ22 в УМ3 состоянии проявляет сверхпластические свойства при $550^{\circ} \mathrm{C}$, а максимальная СП $(m=0.45)$ наблюдается при $600^{\circ} \mathrm{C}$. При температуре $550^{\circ} \mathrm{C}$ максимум СП приходится на скорость $10^{-4} \mathrm{c}^{-1}$,

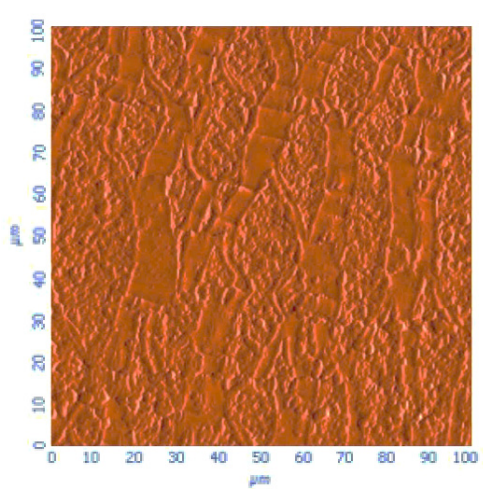

a

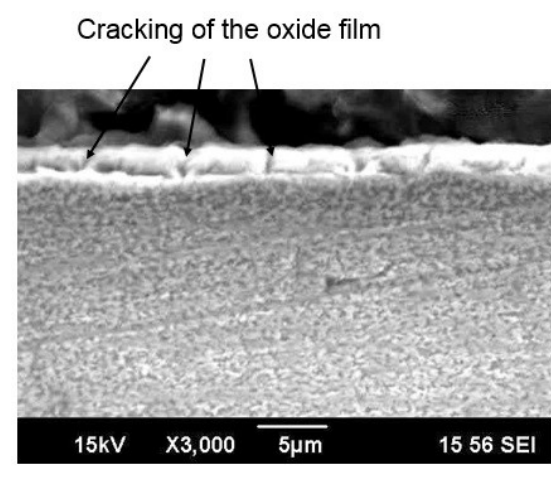

b

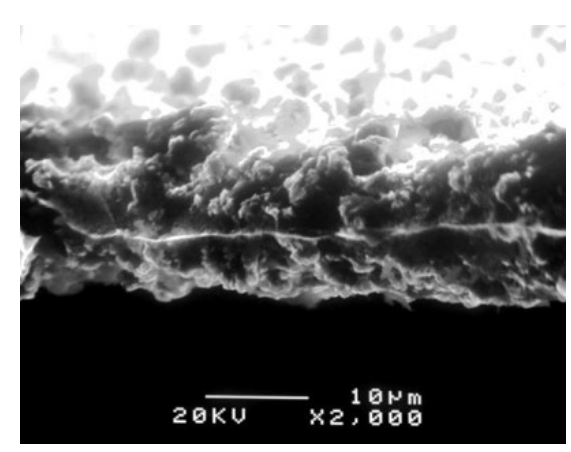

Pис. 4. (Color online) После СП деформации при температуре $550^{\circ} \mathrm{C}$ : сканирующая зондовая микроскопия поверхности рабочей части образцов (a), растровая электронная микроскопия боковой поверхности образцов (b), растровая электронная микроскопия поверхности излома (c).

Fig. 4. (Color online) After SP deformation at a temperature of $550^{\circ} \mathrm{C}$ : scanning probe microscopy of the surface of the working portion of the samples (a), scanning electron microscopy of the lateral surface of the samples (b), scanning electron microscopy of the fracture surface (c). 
а при повышении температуры до $600^{\circ} \mathrm{C}$ максимальные показатели смещаются в сторону более высоких скоростей деформации.

2. Электронно-микроскопическими исследованиями микроструктуры после испытаний на СП не удалось обнаружить поры на отполированной и/или травленой поверхности образцов на установившейся стадии СП течения при растяжении; не было замечено укрупнения зерен. Разрушение образцов при исследованных температурах и ограничение максимального удлинения, вероятно, определяется растрескиванием оксидной плёнки и проникающим окислением в объем образца при его утонении в процессе испытания растяжением.

3. Низкотемпературная СП может вызвать практическую заинтересованность у конструкторов и технологов к использованию высокопрочного титанового сплава ВТ22 для изготовления различных деталей ответственного назначения со сложной пространственной формой. Исходя из высокого потенциала технологической пластичности в условиях низкотемпературной СП, сплав ВТ22 может быть успешно использован для изготовления полых изделий сложной конфигурации при пониженных температурах начиная с $T=600^{\circ} \mathrm{C}$.

Благодарности/Acknowledgements. Работа выполнена в рамках государственного задания ИПСМ РАН № AAAA-A17-117041310221-5. / The present work was accomplished according to the state assignment of IMSP RAS (Reg. No. AAAA-A17-117041310221-5).

\section{Литература/References}

1. R.R. Mulyukov, R.M. Imayev, A.A. Nazarov et al. Sverkhplastichnost' ul'tramelkozernistykh splavov: eksperiment, teoriya, tekhnologii. Moscow, Nauka (2014) 284 p. (in Russian) [P.Р. Мулюков, Р. М. Имаев, А.А. Назаров и др. Сверхпластичность ультрамелкозернистых сплавов: эксперимент, теория, технологии. Москва, Наука (2014) 284 с.]

2. A.A. Arislanov, L. Yu. Goncharova, N. A. Nochovnaya, V.A. Goncharov. Proceedings of VIAM. 10, 4 (2015) (in Russian) [A.А. Арисланов, Л.Ю. Гончарова, Н.А. Ночовная, В.А. Гончаров. Труды ВИАМ. 10, 4 (2015).] Crossref

3. Superplasticity in Advanced Materials-ICSAM-2006. (Ed. by K. F. Zhang). Harbin, China (2006) 864 p.

4. I.I. Ivanov, A. V. Sokolov, V.S. Sokolov, A.E. Shelest, A.R. Paltievich. Osnovy teorii obrabotki metallov davleniyem. Moscow, Forum: INFRA-M (2007) 40 p. (in Russian) [И. И. Иванов, А. В. Соколов, В. С. Соколов, А.Е. Шелест, А.Р. Палтиевич. Основы теории обработки металлов давлением. Москва, Форум: ИНФРА-М (2007) 144 с.]

5. V.A. Golenkov, A.M. Dmitriev, V.D. Kuhar, S. Yu. Radchenko,S. P.Yakovlev, S. S. Yakovlev.Spetsial'nyye tekhnologicheskiye protsessy i oborudovaniye obrabotki davleniyem. Moscow, Mashinostroyeniye (2004) 464 р. (in Russian) [В.А. Голенков, А. М. Дмитриев, В.Д. Кухарь, С.Ю. Радченко, С.П. Яковлев,
C. С. Яковлев. Специальные технологические процессы и оборудование обработки давлением. Москва, Машиностроение (2004) 464 с.]

6. O.A. Kaibyshev. Nauchnyye osnovy, dostizheniya i perspektivy sverkhplasticheskoy deformatsii. Ufa, Gilem (2000) 149 p. (in Russian) [O.А. Кайбышев. Научные основы, достижения и перспективы сверхпластической деформации. Уфа, Гилем (2000) 149 c.]

7. E. Avtokratova, O. Sitdikov, O. Mukhametdinova, M. Markushev, S.V.S.N. Murty, M.J.N.V. Prasad, B.P. Kashyap. Materials Science Forum. 830-831, 345 (2015). Crossref

8. A.N. Vargin, G.S. Burkhanov, N.C. Dung, V.I. Polkin. The International Scientific Journal. 6, 65 (2013). (in Russian) [А.Н. Варгин, Г.С. Бурханов, Н.С. Зунг, В.И. Полькин. Международный научный журнал. 6, 65 (2013).]

9. F.Z. Utyashev, G.I. Raab. Deformatsionnyye metody polucheniya i obrabotki ul'tramelkozernistykh i nanostrukturnykh materialov. Ufa, Gilem (2013) 376 p. (in Russian) [Ф.3. Утяшев, Г.И. Рааб. Деформационные методы получения и обработки ультрамелкозернистых и наноструктурных материалов. Уфа, Гилем (2013) 376 с.]

10. R.Z. Valiev, I.V. Aleksandrov. Ob'yemnyye nanostrukturnyye metallicheskiye materialy: polucheniye, struktura i svoystva. Moscow, ECC "Academkniga” (2007) 398 p. (in Russian) [Р.3. Валиев, И.В. Александров. Объемные наноструктурные металлические материалы: получение, структура и свойства. Москва, ИКЦ «Академкнига» (2007) 398 с.]

11. R. Ya. Lutfullin, A. A. Kruglov, M. Mh. Mukhametrakhimov, O.A. Rudenko. Letters on materials. 5 (2), 185 (2015) (in Russian) [Р.Я. Лутфуллин, А.А. Круглов, M.Х. Мухаметрахимов, О.А. Руденко. Письма о материалах. 5 (2), 185 (2015).] Crossref

12. O.A. Kaybyshev. Sverkhplastichnost' promyshlennykh splavov. Moscow, Metallurgiya (1984) 264 p. (in Russian) [О.А. Кайбышев. Сверхпластичность промышленных сплавов. Москва, Металлургия (1984) 264 с.]

13. R.R. Mulyukov, R.V. Safiullin, A.A. Kruglov, R. Ya. Lutfullin, A. A. Inozemtsev et al. Nanotekhnologii i nanomaterialy Permskogo kraya. Perm, CNTI (2009) 61 p. (in Russian) [Р. Р. Мулюков, Р.В. Сафиуллин, А. А. Круглов, Р. Я. Лутфуллин, А. А. Иноземцев и др. Нанотехнологии и наноматериалы Пермского края. Пермь, ЦНТИ (2009) 61 с.]

14. E. Yu. Klassman, P.A. Klassman, V.V. Astanin. Perspektivnye Materialy. 12, 218 (2011). (in Russian) [Е. Ю. Классман, В.В. Астанин, П.А. Классман. Перспективные материалы. 12, 218 (2011).]

15. I. V. Ratochka, E. V. Naydenkin, I. P. Mishin, O. N. Lykova. Letters on materials. 8(4s), 543 (2018). $\underline{\text { Crossref }}$

16. E. Yu. Klassman, V.V. Astanin, P.A. Klassman. Perspektivnye Materialy. 7, 14 (2009). (in Russian) [Е.Ю. Классман, В.В. Астанин, П.А. Классман. Перспективные материалы. 7, 14 (2009).]

17. Patent RF № 2320771, 27.03.2008 (in Russian) [Патент РФ № 2320771, 27.03.2008]. 
18. R. Ya. Lutfullin, P.A. Klassman, E. Yu. Klassman. Polucheniye tonkikh listov titanovogo splava VT22 s ul'tramelkozernistoy strukturoy putem izotermicheskoy prokatki: Tekhnologicheskiye rekomendatsii TR 48 INB - 16. Ufa, IMSP RAS (2016) 9 p. (in Russian) [Р.Я. Лутфуллин, П.А. Классман, Е.Ю. Классман. Получение тонких листов титанового сплава ВТ22 с ультрамелкозернистой структурой путем изотермической прокатки: Технологические рекомендации ТР - 48 ИНБ - 16. Уфа, ИПСМ РАН (2016) 9 c.]

19. E. N. Petrov, V. V. Rodionov, E. N. Kuzmin, R. Ya. Lutfullin, R.V. Safiullin. Yacheistyye konstruktsii. Snezhinsk, RFNC - VNIITF (2008) 176 p. (in Russian) [Е. Н. Петров, B.В. Родионов, Э.Н. Кузьмин, Р.В. Сафиуллин. Ячеистые конструкции. Снежинск, РФЯЦ-ВНИИТФ (2008) 176 c.]

20. A. R. Safiullin, R. V. Safiullin, F. F. Safin, A. Kh. Akhunova, S. V. Dmitriev. Perspektivnye Materialy. 15, 114 (2013) (in Russian) [А.P. Сафиуллин, Р.В. Сафиуллин,
Ф.Ф. Сафин, А.Х. Ахунова, С.В. Дмитриев. Перспективные материалы. 15, 114 (2013).]

21. G. A. Salischev, R.M. Galeyev, O.R. Valiakhmetov. Journal of Materials Processing Technology. 116, 165 (2001). Crossref

22. A.P. Zhilyaev, A.I. Pschenichnyuk. Sverkhplastichnost' i granitsy zeren $\mathrm{v}$ ul'tramelkozernistykh materialakh. Moscow, FIZMATLIT (2008) 320 p. (in Russian) [А. П. Жиляев, А. И. Пшеничнюк. Сверхпластичность и границы зерен в ультрамелкозернистых материалах. Москва: ФИЗМАТЛИТ (2008) 320 с.]

23. R. Ya. Lutfullin, M.Kh. Mukhametrakhimov, A. A. Kruglov. Letters on materials. 3(4), 292 (2013) (in Russian) [Р.Я. Лутфуллин, М.Х. Мухаметрахимов, А. А. Круглов. Письма о материалах. 3 (4), 292 (2013).] Crossref

24. A. V. Sisanbayev, A. A. Kruglov, R. Ya. Lutfullin, . Chemical Physics and Mesoscopy. 17(4), 595 (2015) p. (in Russian) [А.В. Сисанбаев, А.А. Круглов, Р.Я. Лутфуллин. Химическая физика и мезоскопия. 17(4), 595 (2015).] 